\title{
Analysis of Factors Affecting the Length of Stay in the Emergency Department for Critically III Patients Transferred to Regional Emergency Medical Centers
}

Hyungbok Lee

Seoul National University Hospital

Sangrim Lee

Seoul National University Hospital

Hyeoneui Kim ( $\square$ ifilgood@snu.ac.kr)

Seoul National University

\section{Research Article}

Keywords: Interhospital Transfer, critically ill patient, length of stay in the emergency department, prediction model using electronic medical records, Emergency Medical Service

Posted Date: January 6th, 2022

DOI: https://doi.org/10.21203/rs.3.rs-1196218/v1

License: (우 (i) This work is licensed under a Creative Commons Attribution 4.0 International License. Read Full License 


\section{Abstract}

\section{Background}

Transferring an emergency patient to another emergency department (ED) is necessary when she/he is unable to receive necessary treatment from the first visited ED, although the transfer poses potential risks for adverse clinical outcomes and lowering the quality of emergency medical services by overcrowding the transferred ED. This study aimed to understand the factors affecting the ED length of stay (LOS) of critically ill patients and to investigate whether they are receiving prompt treatment through Interhospital Transfer (IHT).

\section{Methods}

This study analyzed 968 critically ill patients transferred to the ED of the study site in 2019. Machine learning based prediction models were built to predict the ED LOS dichotomized as greater than 6 hours or less. Explanatory variables in patient characteristics, clinical characteristics, transfer-related characteristics, and ED characteristics were selected through univariate analyses.

\section{Results}

Among the prediction models, the Logistic Regression (AUC 0.85) model showed the highest prediction performance, followed by Random Forest (AUC 0.83) and Naïve Bayes (AUC 0.83). The Logistic Regression model suggested that the need for emergency operation or angiography (OR 3.91,95\% $\mathrm{Cl}=1.65-9.21$ ), the need for Intensive Care Unit (ICU) admission (OR 3.84, 95\% Cl=2.53-5.83), fewer consultations (OR 3.57, $95 \% \mathrm{Cl}=2.84-4.49$ ), a high triage level (OR 2.27, 95\% $\mathrm{Cl}=1.43-3.59$ ), and fewer diagnoses (OR $1.32,95 \%$ $\mathrm{Cl}=1.09-1.61$ ) coincided with a higher likelihood of 6-hour-or-less stays in the ED. Furthermore, an interhospital transfer handoff led to significantly shorter ED LOS among the patients who needed emergency operation or angiography, or ICU admission, or had a high triage level.

\section{Conclusions}

The results of this study suggest that patients prioritized in emergency treatment receive prompt intervention and leave the ED in time. Also, having a proper interhospital transfer handoff before IHT is crucial to provide efficient care and avoid unnecessarily longer stay in ED.

\section{Introduction}

Interhospital Transfer (IHT) refers to the transfer of a patient to another hospital where the appropriate treatment for the patient is available [1]. In cases where an emergency patient cannot receive specialized treatment at the first visited Emergency Department (ED), it is inevitable that the patient is transferred to a hospital where the necessary treatment is available $[2,3]$. However, IHT of emergency patients can negatively affect the patient outcome due to the additional harm incurred during transport and delays in treatment $[4,5,6]$. Also, emergency patients who have been transferred require more resources and longer 
stays in the ED than the patients who directly visited the ED, thus facing higher medical costs $[7,8,14,15]$. A critically ill patient with a high triage level who is transferred to another hospital tends to require more medical resources and stay in the ED longer $[7,8,9]$. These can cause overcrowding of the ED, and in turn, reduce the quality of Emergency Medical Services (EMS) [10-12]. In fact, this vicious cycle that IHT of emergency patients created has been reported in many studies [4-8, 13-15].

However, quite a few studies still recommend IHT for critically ill patients with high triage levels although the risks, to increase the chance of proper treatment [2,3,16-19]. Prior studies showed that IHT present more benefits than risks to emergency patients who are critically ill and in need of specialized treatment, $[16,17]$. Especially, for patients who require emergency operation or angiography or need to be admitted into the intensive care unit (ICU), interhospital transfer was reported to increase the likelihood of receiving the necessary treatment $[2,3,18,19]$.

Obviously, there are many factors contributing to the success of interhospital transfers of critically ill patients that need to be carefully considered before making the transfer decision. It is particularly important to follow the protocols on an interhospital transfer handoff, which can help confirm the availability of the required treatment beforehand and minimize the risks that IHT induce [20].

The length of stay (LOS) in the ED can serve as the important criterion to assess the quality of EMS and many countries have policies in place to maintain ED LOS within a reasonable range [16]. In Korea, emergency medical institutions are evaluated based on whether the patients with severe emergency diagnosis stay in the ED for 6 hours or less [21]. The 2019 statistics on Korea EMS reported that $49 \%$ of all ED patients in Korea stayed in the ED for 2 hours or less [22]. However, the mean LOS in the ED of severe diagnosis patients was 5.98 hours, and that of the region where the study hospital was located was 8.45 hours. Generally, it is reported that the patients with severe emergency diagnosis tend to stay longer in the ED [23].

The wide use of Electronic Medical Records (EMR) enabled patient diagnosis and treatment decisions are made based on the accumulated clinical data [10]. Previous research on IHT primarily studied the general effects of IHT on patient outcome [2-6] or patient safety during transport $[13,14,20]$. Although many studies have investigated the issues around LOS in the ED, they had little intention to identify the factors affecting the ED LOS or overcrowding $[10,24,30]$. Furthermore, few studies have investigated the ED LOS among transferred patients in relation to the quality of EMS. Thus, to understand the factors that affect the LOS in the ED for critically ill patients who were transferred, this study performed a retrospective analysis of EMR data. This study specifically aimed to answer the following questions:

1) What are the factors that lead to 6-hours-or-less stays in the ED, which is the passable cut-off criterion for evaluation of emergency medical institutions in Korea?

2) Are the critically ill patients receiving timely treatment through IHT?

\section{Materials And Methods}




\subsection{Sample}

Among the adult patients who were transferred to the ED of the study site between January 1 and December 31, 2019, this study analyzed only the critically ill patients categorized as level 1 or level 2 on the Korean Triage and Acuity Scale (KTAS). The KTAS is a scale used to classify emergency patients into 5 levels, where level 1 and level 2 are considered critically ill emergency patients. Level 1 indicates a threat to life or limbs that require immediate, active treatment, while level 2 indicates a potential threat to life or limbs that require urgent treatment following doctor's directions or other medical directions [31, 32]. Level 1 patients who were dead on arrival were not included. The study site is a 1,761-bed tertiary teaching hospital located in a metropolitan area.

\subsection{Data Source}

As the aim of this study was to understand the factors that affect the LOS in the ED among the critically ill patients transferred from another hospital, variables that were known to affect the LOS in the ED from previous studies were extracted from the clinical data warehouse of the Seoul National University Hospital.

The variables extracted for this study were as follows. Patient characteristics included sex, age group, day of visit, time of visit, type of visit, and triage level. Clinical characteristics included the diagnosis based on Korean Classification of Disease-6[33], the total number of diagnoses, and whether the diagnoses were among the severe emergency diagnosis including four major severe emergency diagnoses (i.e., acute myocardial infarction, stroke, multiple trauma, and cardiac arrest). Whether the patient needed emergency operation or angiography, whether the patient needed admission to the ICU, and the number of consultations during ED stay were also included as clinical characteristics. Transfer-related characteristics included whether there was prior communication between the referring and accepting hospitals, along with the region and type of referring hospital. ED characteristics of the accepting hospital (i.e., the study site) included the daily number of patients, the number of patients by triage levels, and the subject's LOS in the ED calculated from the times of admission and discharge.

\subsection{Data Preparation}

The LOS in the ED, which is the outcome variable that this study aimed to predict, was first calculated as the interval between admission to and discharge from the ED. This interval was then dichotomized into exceeding 6 hours (0) or not (1). This decision was based on the criterion of 6-hour-or-less stay in the ED, which is adopted by the Korean Ministry of Health and Welfare to evaluate the performance of emergency medical institutions involved in managing severe emergency diagnosis patients [15].

\subsubsection{Patient Characteristics}

Age, day of visit, time of visit, and type of visit may affect the LOS in the ED, and a higher triage level can lead to a longer stay in the ED [24-27]. Age was grouped into under 60 and over 60 , the day of visit was categorized into weekdays and weekend, and the time of visit was divided into daytime (09:00-17:59) and 
nighttime (18:00-08:59). The type of visit was categorized into disease versus injury, and the triage level indicated the KTAS severity level (i.e., KTAS level 1 and 2).

\section{2-3-2. Clinical Characteristics}

The total number of diagnoses and the number of consultations increase with the complexity of the emergency condition $[24,25,27,28]$. The number of consultations was coded with $0,1,2$, and 3 or more, and the total number of diagnoses was with 1, 2, 3, and 4 or more. Receiving specialized treatment-namely, emergency operation or angiography-and ICU admission can be a primary reason behind IHT [34]. Thus, the presence of severe emergency diagnosis, the need for emergency operation or angiography, and the need for ICU admission were included as a binary variable. An IHT event was treated as having a proper interhospital handoff when the transfer occurred after the acceptance of the receiving hospital upon discussion between the referring and receiving hospitals. Alternatively, an IHT event occurred without prior communication or occurred despite the declination from the receiving hospital due to the inability to accommodate the patient, were treated as not having proper interhospital handoff communication.

\subsubsection{Transfer-related Characteristics}

As the transport distance between hospitals may affect the prognoses of emergency patients, the region of the referring hospital was categorized into two groups based on whether it was in the same region as the study site (i.e., receiving hospital) or not $[13,35]$. Patients visiting the ED from long-term care facilities may experience longer stays due to the chronic and complex nature of their illnesses [35]. Therefore, the referring hospital was categorized into short-term care hospitals and long-term care hospitals.

\subsubsection{Characteristics of the ED at the accepting hospital}

The occupancy rate (\%) is an indicator of ED overcrowding and calculated as (number of patients $x$ average LOS)/ (standard number of beds $\times$ number of days in month $\times 24$ hours). In this study, the occupancy rate (\%) was calculated as (daily number of patients $\times$ average LOS)/ (standard number of beds $\times 24$ hours) [36] to represent daily ED overcrowding.

\subsection{Variable Selection}

A preliminary analysis was performed to identify the variables that effectively predict 6-hours-or-less ED stay among the 39 potential predictors selected from the four areas explained above. The data were divided into two groups based on whether the LOS exceeded 6 hours or not. Then, chi-square tests were performed on categorical variables and independent sample t-tests were performed on continuous variables to examine the between group differences in the variables. The variables that showed statistically significant differences between the two groups were selected as the independent variables to predict the LOS in the ED.

\subsection{Data Analysis}

Descriptive statistics and univariate analyses were performed using SPSS 23.0[SPSS, Inc., Chicago, IL, USA]. The prediction models for the ED LOS of 6 hours or less were constructed using WEKA 3-9- 
3[University of Waikato, New Zealand]. The machine learning algorithms applied to construct the prediction models were logistic regression, random forest, decision tree, support vector machine, naïve Bayes, and multilayer perceptron. To validate the performances of the models, 10 -fold cross validation was performed and accuracy, precision, recall, F-measure, the Receiver Operating Characteristic (ROC) curve, and the Area Under the Curve (AUC) of the ROC were produced.

\subsection{Ethical Considerations}

This study was approved by the Institutional Review Board (H-2009-156-1159) of the study site. This study carries minimal risk, does not include identifiable information, and had data encrypted for storage.

\section{Results}

\subsection{Relationship between Subject Characteristics and Length of Stay (LOS)}

\section{3-1-1. Patient Characteristics}

The characteristics of the 968 subjects included in this study are summarized in Table 1. More than half of the subjects was male (56.4\%) and close to $70 \%$ was over 60 ; neither variable showed a significant difference in the ED LOS. The day of visit, with much more visits on weekdays (684 patients) than on weekends (284 patients), showed a significant difference in the ED LOS $(p=.015)$. A little over half of the patients visited ED during the daytime and the reason for the visit was largely disease related (95.5\%). Neither of these variables showed a significant difference in the ED LOS. The triage level, where $20 \%$ of the subject fell on KTAS level 1 , showed a significant difference in the ED LOS $(p<.001)$.

\section{3-1-2. Clinical Characteristics}

There were 366 patients with severe emergency diagnosis, of which 150 were with the four major severe emergency diagnoses. A small number of patients needed emergency operation or angiography $(6.8 \%$; $\mathrm{N}=66$ ), while as many as 307 patients needed admission to the ICU. Most of the patients needed consultations: 443 patients needed one consultation and 124 needed three or more consultations. When classified based on the 22 diagnosis groups of the Korean Classification of Disease- $6,38 \%$ of the patients was having a diagnosis related to neoplasms, $25 \%$ was circulatory, and $23 \%$ was respiratory. All the clinical characteristics showed significant differences in the ED LOS $(p<.001)$.

\section{3-1-3. Transfer-related Characteristics}

No difference was observed in the LOS by the region of referring hospitals. Most of the patients were transferred from short-term care hospitals and the type of referring hospital showed a significant difference in the ED LOS $(p<.001)$. Also, there were 712 patients transferred without a proper interhospital handoff and this handoff communication showed a significant difference in the ED LOS $(p=.001)$.

3-1-4. Characteristics of the ED at the accepting hospital 
Table 2 presents the characteristics of the ED at the accepting hospital. On average, 144.2 patients visited the ED per day with varying KTAS triage levels. The ED LOS differed significantly by the average daily visit count $(p=.005)$ and KTAS level $3(p=.008)$. The ED LOS differed significantly by the average occupancy rate of the ED $(p<.001)$.

The relationship between the interhospital handoff communication and the ED LOS is shown in Table 3. The ED LOS of transferred level 1 patients was significantly shorter $(p=.004)$ when proper interhospital handoff had occurred; however, interhospital handoff did not make a difference in the ED LOS for the level 2 patients. The LOS in the ED was significantly shorter when proper interhospital handoff had occurred prior to the transfer among the patients in need of emergency operation or angiography $(p=.004)$ or ICU admission $(p<.001)$, and the patients with only one consultation $(p=.002)$.

\subsection{Prediction of the Length of Stay in the Emergency Department}

Prediction models were constructed for 6-hour-or-less stays in the ED, with sex, age, triage level, severe emergency diagnosis, need for emergency operation or angiography, need for ICU admission, the number of consultations, and the number of diagnoses as the independent variables. Table 4 shows the prediction performance of the six models constructed using different modeling methods. Based on the AUC of ROC, logistic regression showed the best performance (0.85) followed by random forest (0.83) and naïve Bayes (0.83) (Figure 1). Pair-wise comparisons of the models showed the differences in AUC between models were all significant at a 95\% significance level except for the random forest and naïve Bayes that showed the identical AUC.

The factors affecting 6-hour-or-less stays in the ED were analyzed based on the logistic regression model. As indicated by the Odds Ratio (OR) in Figure 2, a patient who needed emergency operation or angiography (OR 3.90), or ICU admission (OR 3.84); or had fewer consultations (OR 3.57), a high triage level (OR 2.27), and fewer diagnoses (OR 1.32) were more likely to stay in the ED for 6 hours or less.

\section{Discussion}

This study aimed to identify the critical factors for timely treatment of critically ill patients transferred between hospitals. Among the 6 predictive modeling methods applied, logistic regression showed the best prediction performance. The results of the logistic regression model revealed the factors that lead to shorter (i.e., 6-hour-or-less) stays in the ED.

The need for emergency operation or angiography had the largest effect (OR 3.90). This result indicates that critically ill patients in need of operation or angiography are likely to receive the needed treatment in 6 hours or less. The ED of the study site implements critical pathways for patients with severe emergency diagnoses requiring emergency operation or angiography, such as acute myocardial infarction, stroke, and multiple trauma. 
The implementation of critical pathways for critically ill patients may be a reason that prompts emergency operation or angiography is possible. Indeed, many EDs implement critical pathways to provide critically ill patients with specialized treatment timely, and critical pathways positively affect the disease prognosis and the ED LOS [37-39]. However, note that respiratory illnesses (OR 0.65) and endocrine disorders (OR 0.26 ) had a significantly higher likelihood of ED stays exceeding 6 hours, which suggests the need for developing a critical pathway program for patients with severe emergency diagnoses that do not require emergency operation or angiography.

The need for ICU admission had the second-largest effect (OR 3.84). This result suggests that patients who need intensive monitoring and specialized treatment are probably admitted into the ICU in 6 hours or less. This result also indicates that treatment resources are effectively allocated to patients with the highest severity level. The ED of the study site runs an emergency ICU equipped with 20 beds to provide timely treatment to critically ill patients. Additionally, there is a medical team exclusively taking care of critically ill patients that enables rapid hospitalization and effective resource management. As a result, $65.6 \%$ of the patients with the highest triage level (i.e., KTAS level 1) were admitted to the ICU and $70.3 \%$ of them were admitted to the emergency ICU. This result indicates that the designation of an emergency ICU is crucial in providing critically ill patients of high-quality emergency medical services [40, 41].

Fewer consultations were also a significant factor that leads to 6-hour-or-less stays in the ED (OR 3.57). Consultations are known to be one of the main causes of extended ED stay [39, 41-43]. In this study, this effect was even more evident for the patients transferred after proper IHT handoff. This result is not surprising because the number of consultations indicates the high severity and complexity of the illness.

Patients with a high triage level of KTAS level 1 were likely to stay 6-hour-or-less in the ED (OR 2.27). This result coincides with previous studies reporting patients with the highest triage level tend to have shorter stays in the ED, which is an indication of effective resource allocation in ED [44, 45]. Certainly, operating the dedicated medical team for critically ill patients along with the emergency ICU in the study site seems to serve a crucial role in providing adequate emergency treatment for critically ill patients. It will be worth investigating if this program would show the same effect for KTAS level 2 patients who are also classified as critically ill patients.

Having a proper IHT handoff prior to transferring the patient led to a significantly shorter LOS in the ED in most cases [Table 3]. This result coincides with those of previous studies that reported the absence of an IHT handoff negatively affects the length of hospital stay and outcome $[13,14]$. Because a proper IHT handoff is an important process for the receiving hospital to confirm important patient information and secure the required resources before the patient arrives. However, interhospital transfer guidelines that indicate an IHT handoff are an important step to follow before transferring patient is often not strictly followed [46].

This study showed that specialized resources such as emergency operation or angiography and ICU admission, triage level, the number of consultations, and the number of diagnoses are the important factors to consider maintaining the ED LOS as recommended by the Korean Ministry of Health and 
Welfare. Considering that the primary reason for choosing $\mathrm{IHT}$ although the risk is to receive specialized treatment unavailable in the current hospital [2-5], the results of this study are encouraging in that transferred critically ill patients were receiving proper specialized treatments at the transferred ED.

This study has limitations. As this study was conducted in a single hospital including only the critically ill patients categorized as KTAS level 1 and 2, the results of this study may not be generalized to other hospitals and KTAS level 3 and 4 patients. Additionally, this study did not consider mortality and medical costs. Therefore, the results of this study do not stipulate the effect of the IHT on patient outcome. Although these limitations, this study adds useful information on IHT of critically ill patients by identifying the factors that affect their LOS in the ED.

\section{Conclusions}

This study investigated the factors that affected 6-hour-or-less stays in the ED for critically ill patients who were transferred to a regional emergency medical center. The results showed that patients in need of emergency operation or angiography, or admission to ICUs, and patients with a high triage level were more likely to stay in the ED for 6 hours or less. This result suggests that IHT allows patients with high severity and in need of specialized treatment to receive prompt treatment following IHT.

\section{Declarations}

\section{Ethics approval and consent to participate}

This retrospective study was approved by the Institutional Review Board of the Seoul National University Hospital(H-2009-156-1159). The requirement for informed consent was waived by this institutional review board. Only the researcher can access the data. All methods throughout the study were performed in accordance with the relevant guidelines and regulations.

\section{Consent for publication}

Not applicable.

\section{Availability of data and materials}

The data of this research were extracted from the Seoul National University Hospital data warehouse. The data of this research were non- public data. Also, personally identifiable information was excluded. This data used them for non-commercial purposes, without breaching participant confidentiality.

The datasets generated during and analyzed during the current study are not publicly available due to the sensitive nature and the data use agreement condition of the medical record data but are available from the corresponding author on reasonable request.

\section{Competing interests}


The authors declare that they have no competing interests.

\section{Funding}

This study was performed without funding.

\section{Authors' contributions}

Hyung-bok Lee wrote the manuscript text, performed data analysis, and prepared tables and figures as the main author of this study. Sang-Rim Lee wrote the manuscript text and reviewed data analysis as the second author of this study. Hyeoneui Kim edited the manuscript and data analysis as a Corresponding author of this study. All authors reviewed the manuscript.

\section{Acknowledgements}

None.

\section{Authors' information (optional)}

${ }^{1}$ Emergency Nursing Department, Seoul National University Hospital, Seoul, Republic of Korea

${ }^{2}$ College of Nursing, Seoul National University, Seoul, Republic of Korea

\section{References}

1. Margaret, M. (2006). Transporting critically ill patients: new opportunities for nurses. Nurs Stand, 20(36), 46-48.

2. Ivanusa, M. (2005). Reducing mortality in myocardial infarction: goal should be interhospital transfer for primary angioplasty. BMJ: 330(7502), 1271.

3. Merlo, A. E., Chauhan, D., Pettit, C., Hong, K. N., Saunders, C. R., Chen, C., \& Russo, M. J. (2016).

Outcomes following emergent open repair for thoracic aortic dissection are improved at higher volume centers in direct admissions and transfers. J Cardiothorac Surg, 11(1), 118.

4. Gordon, H. S., \& Rosenthal, G. E. (1996). Impact of interhospital transfers on outcomes in an academic medical center. Implications for profiling hospital quality. Med Care, 295-309.

5. Castillo-Angeles, M., Uribe-Leitz, T., Jarman, M., Jin, G., Feeney, T., Salim, A., \& Havens, J. M. (2019). Transferred emergency general surgery patients are at increased risk of death: a NSQIP propensity score matched analysis. J Am Coll Surg, 228(6), 871-877.

6. Mohr, N. M., Harland, K. K., Shane, D. M., Ahmed, A., Fuller, B. M., \& Torner, J. C. (2016). Inter-hospital transfer is associated with increased mortality and costs in severe sepsis and septic shock: An instrumental variables approach. J Crit Care, 36, 187-194.

7. Hernandez-Boussard, T., Davies, S., McDonald, K., \& Wang, N. E. (2017). Interhospital facility transfers in the United States: a nationwide outcomes study. J Patient Saf, 13(4), 187-191. 
8. Mueller, S., Zheng, J., Orav, E. J., \& Schnipper, J. L. (2019). Inter-hospital transfer and patient outcomes: a retrospective cohort study. BMJ Qual Safety, 28(11), e1-e1.

9. Faine, B. A., Noack, J. M., Wong, T., Messerly, J. T., Ahmed, A., Fuller, B. M., \& Mohr, N. M. (2015). Interhospital transfer delays appropriate treatment for patients with severe sepsis and septic shock: a retrospective cohort study. Crit Care Med, 43(12), 2589-2596.

10. Kulstad, E. B., Sikka, R., Sweis, R. T., Kelley, K. M., \& Rzechula, K. H. (2010). ED overcrowding is associated with an increased frequency of medication errors. Am J Emerg Med, 28(3), 304-309.

11. Vieth, T. L., \& Rhodes, K. V. (2006). The effect of crowding on access and quality in an academic ED. Am J Emerg Med, 24(7), 787-794.

12. Sprivulis, P. C., Da Silva, J. A., Jacobs, I. G., Jelinek, G. A., \& Frazer, A. R. (2006). The association between hospital overcrowding and mortality among patients admitted via Western Australian emergency departments. Med J Aust, 184(5), 208-212.

13. Han, S. S., Jung, K. W., Kwon, J. S., Kim, J. Y., Choi, S. C., \& Lee, K. J. (2011). Problems with transferring major trauma patients to emergency medical center of a university hospital from another medical center. J Trauma Inj, 24(2), 118-124.

14. Hains, I. M., Marks, A., Georgiou, A., \& Westbrook, J. I. (2011). Non-emergency patient transport: what are the quality and safety issues? A systematic review. Int J Qual Health Care, 23(1), 68-75.

15. Yoon, B. S., Choa, M. H., Kong, T. Y., Joo, Y. S., Ko, D. R., Hwang, Y. J., Chung, S.P., \& Lee, H. S. (2018). The effect of time target on overcrowding and clinical quality in the ED: a systematic review and metaanalysis. J Korean Soc Emerg Med, 29(2), 170-178.

16. Kim, M. G., Shin, T. G., Jo, I. J., Kim, W. Y., Ryoo, S. M., Chung, S. P., ... Hwang, S. Y. (2018). Characteristics and outcomes of patients with septic shock who transferred to the emergency department in tertiary referral center: multicenter, retrospective, observational study. J Korean Soc Emerg Med, 29(5), 465-473.

17. Nuño, M., Patil, C. G., Lyden, P., \& Drazin, D. (2012). The effect of transfer and hospital volume in subarachnoid hemorrhage patients. Neurocrit Care, 17(3), 312-323.

18. Colgrave, N., Ibbett, I., \& Thani, N. (2019). Transfer times and patient outcomes-A review of head injuries requiring surgery in Tasmania 2006-2017. J Clin Neurosci, 64, 122-126.

19. Hill, A. D., Fowler, R. A., \& Nathens, A. B. (2011). Impact of interhospital transfer on outcomes for trauma patients: a systematic review. J Trauma, 71(6), 1885-1901.

20. Feazel, L., Schlichting, A. B., Bell, G. R., Shane, D. M., Ahmed, A., Faine, B., Nugent, A., \& Mohr, N. M. (2015). Achieving regionalization through rural interhospital transfer. Am J Emerg Med, 33(9), 12881296.

21. Emergency Medical Service Act, Article 17 (Evaluation of Emergency Medical Institutions,

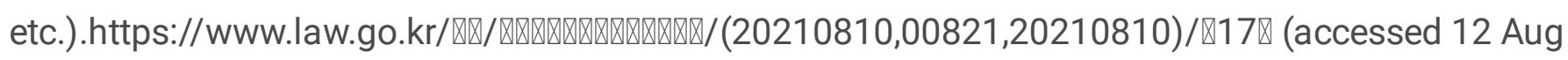
2021).

22. 2019 National Emergency Department Information System (NEDIS) Annual Statistics Report. https://www.e-gen.or.kr/nemc/statistics_annual_report.do?brdclscd=02 (accessed 12 Aug 2021). 
23. 2019 Status Report on Emergency Department Visits for Severe Emergency Illnesses (National Emergency Medical Center). https://www.e-gen.or.kr/nemc/statistics_annual_report.do?brdclscd=03 (accessed 12 Aug 2021).

24. Shin, S. D., Jo, Y. H., Cheon, S. B., Jung, S. K., Kwak, Y. H., Rhee, J. E., \& Suh, G. J. (2004). Effect of emergency department overcrowding on the outcome of patient care: a pilot study. J Korean Soc Emerg Med, 15(1), 1-7.

25. Chung, S. H., \& Hwang, J. I. (2009). Patient characteristics associated with length of stay in emergency departments. Health Policy and Management, 19(3), 27-44.

26. Holland, C. M., Lovasik, B. P., Howard, B. M., McClure, E. W., Samuels, O. B., \& Barrow, D. L. (2017). Interhospital transfer of neurosurgical patients: implications of timing on hospital course and clinical outcomes. Neurosurgery, 81(3), 450-457.

27. Downing, A., Wilson, R. C., \& Cooke, M. W. (2004). Which patients spend more than 4 hours in the accident and emergency department? J Public Health, 26(2), 172-176.

28. Kim, E. J., Lim, J. Y., Ryu, J. S., Cho, S. H., Bae, N. R., \& Kim, S. S. (2011). A stay time optimization model emergency medical center (EMC). KASHCN,18(2), 81-87.

29. Kim, W. H., Choi, H. J., Im, T. H., Kang, B. S., \& Kang, H. G. (2009). Effect of emergency autoconsultation system (EACS) on length of stay of specialty consultation patients in the emergency department. J Korean Soc Emerg Med, 20(2), 155-162.

30. Vieth, T. L., \& Rhodes, K. V. (2006). The effect of crowding on access and quality in an academic ED. Am J Emerg Med, 24(7), 787-794.

31. Enforcement Regulation of the Emergency Medical Service Act, Article 18-3, Section 2.

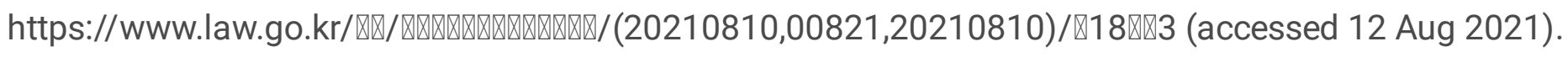

32. Ministry of Health and Welfare. Korean Triage and Acuity Scale adult/child training program: Participant's manual version 1.0 [Internet]. Sejong: J Korean Soc Emerg Med; c2014 [cited 2018 an20].https://www.prism.go.kr/homepage/entire/downloadResearchAttachFile.do? workKey $=001 \&$ fileType $=$ CPR\&seqNo=002\&pdfConvYn=N\&researchld $=1351000-201400241$ (accessed 12 Aug 2021).

33. Korean Classification of Disease educational (6th edtion), Statistics Korea(2011).(2011). http://www.hira.or.kr/rd/insuadtcrtr/bbsView.do? pgmid=HIRAA030069000400\&brdScnBltNo $=4 \&$ brdBItNo $=49194$

34. Kindermann, D. R., Mutter, R. L., Houchens, R. L., Barrett, M. L., \& Pines, J. M. (2015). Emergency department transfers and transfer relationships in United States hospitals. Acad Emerg Med, 22(2), 157-165.

35. Lee, D., Ahn, K. O., Shin, S. D., Park, H. A., Roa, Y. S., Cha, W. C., \& Lee, S. C. (2014). Impacts of urbanization on delay in transferred ischemic stroke patients. J Korean Soc Emerg Med, 25(4), 392400.

36. Lee, J. H., \& Cho, S. H. (2018). Effect of crowding and nurse staffing on time to antibiotic administration for patients with pneumonia in an emergency department. J Korean Acad Nurs Admin, 
24(2), 107-117.

37. Kim, H. W., Hong, T. H., Lee, S. H., Jung, M. J., \& Lee, J. G. (2015). The influence of how the trauma care system is applied at the trauma center: the initial experience at single trauma center. J Trauma Inj, 28(4), 241-247.

38. Yun, Y. O., Kim, M. Y., Kim, W. J., Kang, Y. J., Park, J. O., \& Park, K. H. (2011). Reduction of length of stay in emergency room by using critical pathway for stroke patients. J Korean Acad Nurs Admin, 17(1), $66-73$.

39. Shim, H., Jang, J. Y., Lee, J. G., Kim, S., Kim, M. J., Park, Y. S., ... Kim, S. H.(2012). Application of critical pathway in trauma patients. J Trauma Inj, 25(4), 159-165.

40. Lim, D. W., Sung, W. Y., Lee, J. Y., Lee, W. S., Seo, S. W., \& Lee, K. T. Impact of decreased intensive care unit bed capacity on the emergency department length of stay and clinical outcomes of critically ill patients. J Korean Soc Emerg Med, 32(2), 170-178.

41. McConnell, K. J., Richards, C. F., Daya, M., Bernell, S. L., Weathers, C. C., \& Lowe, R. A. (2005). Effect of increased ICU capacity on emergency department length of stay and ambulance diversion. Ann Emerg Med, 45(5), 471-478.

42. Lee, P. A., Rowe, B. H., Innes, G., Grafstein, E., Vilneff, R., Wang, D., van Rheenen, S., \& Lang, E. (2014). Assessment of consultation impact on emergency department operations through novel metrics of responsiveness and decision-making efficiency. CJEM, 16(3), 185-192.

43. Mun, S. W., Jeong, S. G., Oh, Y. M., Choe, S. M., Choe, G. H., Park, K. N., \& Oh, J. S. (2009). Effect of issuing of hospitalization sheets by emergency department on shortening length of stay. J Korean Soc Emerg Med, 20(1), 10-19.

44. Bukhari, H., Albazli, K., Almaslmani, S., Attiah, A., Bukhary, E., Najjar, F., ... Eldin,A. S. (2014). Analysis of waiting time in emergency department of Al-Noor Specialist Hospital, Makkah, Saudi Arabia. Open Journal of Emergency Medicine, 2(04), 67.

45. Yoon, P., Steiner, I., \& Reinhardt, G. (2003). Analysis of factors influencing length of stay in the emergency department. CJEM, 5(3), 155-161.

46. Ahn, K. O., Hong, J. Y., Kim, Y., \& Jung, K. Y. (2006). Appropriate interhospital transfer of emergent patients. J Korean Soc Emerg Med, 17(2), 138-145.

\section{Tables}

[Table 1. Relationship between Subject Characteristics and Length of Stay] 


\begin{tabular}{|c|c|c|c|c|c|c|c|c|c|}
\hline \multirow{2}{*}{$\begin{array}{l}\text { Category } \\
\text { Total }\end{array}$} & & \multirow{2}{*}{$\begin{array}{l}N \\
968\end{array}$} & \multirow{2}{*}{$\begin{array}{l}\% \\
100.0 \%\end{array}$} & \multirow{2}{*}{$\begin{array}{l}\text { Mean } \\
12.09\end{array}$} & \multirow{2}{*}{$\begin{array}{l}\text { SD } \\
13.09\end{array}$} & \multicolumn{2}{|c|}{ Criteria $6 \mathrm{hr}$} & \multirow[b]{2}{*}{$\begin{array}{l}\text { chi- } \\
\text { square }\end{array}$} & \multirow[b]{2}{*}{$\begin{array}{l}\mathrm{p}- \\
\text { value }\end{array}$} \\
\hline & & & & & & $<6 \mathrm{hr}$ & $>6 \mathrm{hr}$ & & \\
\hline \multirow[t]{2}{*}{ Sex } & $M$ & 546 & $56.4 \%$ & 12.45 & 13.57 & 220 & 326 & \multirow[t]{2}{*}{0.14} & \multirow[t]{2}{*}{.742} \\
\hline & $\mathrm{F}$ & 422 & $43.6 \%$ & 11.63 & 12.44 & 175 & 247 & & \\
\hline \multirow[t]{2}{*}{ Age } & under 60 & 291 & $30.1 \%$ & 10.93 & 11.68 & 129 & 162 & \multirow[t]{2}{*}{2.14} & \multirow[t]{2}{*}{.154} \\
\hline & over 60 & 677 & $69.9 \%$ & 12.59 & 13.62 & 266 & 411 & & \\
\hline \multirow[t]{2}{*}{ Visit Day } & Weekday & 684 & $70.7 \%$ & 12.81 & 13.66 & 262 & 422 & \multirow[t]{2}{*}{6.04} & \multirow[t]{2}{*}{.015} \\
\hline & Weekend & 284 & $29.3 \%$ & 10.35 & 11.42 & 133 & 151 & & \\
\hline \multirow[t]{2}{*}{ Visit Time } & Day time & 527 & $54.4 \%$ & 12.59 & 13.81 & 217 & 310 & \multirow[t]{2}{*}{0.07} & \multirow[t]{2}{*}{.844} \\
\hline & Night time & 441 & $45.6 \%$ & 11.49 & 12.15 & 178 & 263 & & \\
\hline \multirow[t]{2}{*}{ Visit Type } & Disease & 924 & $95.5 \%$ & 12.31 & 13.27 & 371 & 553 & \multirow[t]{2}{*}{3.60} & \multirow[t]{2}{*}{.061} \\
\hline & Injury & 44 & $4.5 \%$ & 7.48 & 7.15 & 24 & 20 & & \\
\hline \multirow[t]{2}{*}{ Triage } & Level 1 & 194 & $20.0 \%$ & 8.38 & 13.08 & 126 & 68 & \multirow[t]{2}{*}{58.55} & \multirow[t]{2}{*}{$<.001$} \\
\hline & Level 2 & 774 & $80.0 \%$ & 13.02 & 12.93 & 269 & 505 & & \\
\hline \multirow{2}{*}{$\begin{array}{l}\text { Referring } \\
\text { Area }\end{array}$} & In region & 539 & $55.7 \%$ & 12.09 & 13.89 & 235 & 304 & \multirow[t]{2}{*}{3.93} & \multirow[t]{2}{*}{.049} \\
\hline & Out region & 429 & $44.3 \%$ & 12.09 & 12.01 & 160 & 269 & & \\
\hline \multirow{2}{*}{$\begin{array}{l}\text { Referring } \\
\text { Hospital } \\
\text { type }\end{array}$} & $\begin{array}{l}\text { Short-term Care } \\
\text { Hospital }\end{array}$ & 793 & $81.9 \%$ & 12.20 & 0.43 & 348 & 445 & \multirow[t]{2}{*}{17.21} & $<.001$ \\
\hline & $\begin{array}{l}\text { Long-term Care } \\
\text { Hospital }\end{array}$ & 175 & $18.1 \%$ & 16.06 & 1.21 & 47 & 128 & & \\
\hline Interhospital & Yes & 256 & $26.4 \%$ & 10.68 & 12.06 & 127 & 129 & 11.17 & .001 \\
\hline $\begin{array}{l}\text { Transfer } \\
\text { handoff }\end{array}$ & No & 712 & $73.6 \%$ & 12.60 & 13.41 & 268 & 444 & & \\
\hline Severe & None & 640 & $66.1 \%$ & 13.72 & 13.65 & 214 & 426 & 67.67 & $<.001$ \\
\hline Diagnosis & $\begin{array}{l}\text { Severe } \\
\text { Emergency } \\
\text { Diagnosis }\end{array}$ & 216 & $22.3 \%$ & 9.83 & 11.12 & 98 & 118 & & \\
\hline & $\begin{array}{l}\text { 4th Emergency } \\
\text { Diagnosis }\end{array}$ & 112 & $11.6 \%$ & 7.16 & 11.40 & 83 & 29 & & \\
\hline Emergency & Yes & 66 & $6.8 \%$ & 3.22 & 4.28 & 57 & 9 & 60.86 & $<.001$ \\
\hline Operation & & & & & & & & & \\
\hline $\begin{array}{l}\text { or } \\
\text { Angiography }\end{array}$ & No & 902 & $93.2 \%$ & 12.74 & 13.28 & 338 & 564 & & \\
\hline
\end{tabular}




\begin{tabular}{|c|c|c|c|c|c|c|c|c|c|}
\hline \multirow{2}{*}{$\begin{array}{l}\text { ICU } \\
\text { admission }\end{array}$} & Yes & 307 & $31.7 \%$ & 5.64 & 6.72 & 216 & 91 & \multirow[t]{2}{*}{162.56} & \multirow[t]{2}{*}{$<.001$} \\
\hline & No & 661 & $68.3 \%$ & 15.08 & 14.20 & 179 & 482 & & \\
\hline \multirow{4}{*}{$\begin{array}{l}\text { Number of } \\
\text { Consultation }\end{array}$} & 0 & 221 & $22.8 \%$ & 6.22 & 7.26 & 153 & 68 & \multirow[t]{4}{*}{161.88} & \multirow[t]{4}{*}{$<.001$} \\
\hline & 1 & 443 & $45.8 \%$ & 10.07 & 9.92 & 194 & 249 & & \\
\hline & 2 & 180 & $18.6 \%$ & 14.23 & 11.76 & 40 & 140 & & \\
\hline & 3 or more & 124 & $12.8 \%$ & 26.65 & 20.00 & 8 & 116 & & \\
\hline \multirow{4}{*}{$\begin{array}{l}\text { Number of } \\
\text { Diagnosis }\end{array}$} & 1 & 371 & $38.3 \%$ & 8.93 & 10.60 & 204 & 167 & \multirow[t]{4}{*}{54.58} & \multirow[t]{4}{*}{$<.001$} \\
\hline & 2 & 342 & $35.3 \%$ & 13.22 & 13.61 & 122 & 220 & & \\
\hline & 3 & 165 & $17.0 \%$ & 14.96 & 15.07 & 45 & 120 & & \\
\hline & 4 or more & 90 & $9.3 \%$ & 15.59 & 13.84 & 24 & 66 & & \\
\hline \multirow[t]{2}{*}{ Neoplasms } & Yes & 376 & $38.8 \%$ & 14.29 & 12.87 & 110 & 266 & \multirow[t]{2}{*}{33.96} & \multirow[t]{2}{*}{$<.001$} \\
\hline & No & 592 & $61.2 \%$ & 10.69 & 13.04 & 285 & 307 & & \\
\hline \multirow[t]{2}{*}{ Endocrine } & Yes & 32 & $3.3 \%$ & 18.71 & 18.72 & 3 & 29 & \multirow[t]{2}{*}{13.54} & \multirow[t]{2}{*}{$<.001$} \\
\hline & No & 936 & $96.7 \%$ & 11.86 & 12.80 & 392 & 544 & & \\
\hline \multirow[t]{2}{*}{ Circulatory } & Yes & 242 & $25.0 \%$ & 8.55 & 12.52 & 141 & 101 & \multirow[t]{2}{*}{40.72} & \multirow[t]{2}{*}{$<.001$} \\
\hline & No & 726 & $75.0 \%$ & 13.27 & 13.07 & 254 & 472 & & \\
\hline \multirow[t]{2}{*}{ Respiratory } & Yes & 226 & $23.3 \%$ & 15.32 & 14.58 & 62 & 164 & \multirow[t]{2}{*}{21.83} & \multirow[t]{2}{*}{$<.001$} \\
\hline & No & 742 & $76.7 \%$ & 11.11 & 12.44 & 333 & 409 & & \\
\hline
\end{tabular}

[Table 2. Emergency Department Characteristics of the Accepting Hospital] 


\begin{tabular}{|c|c|c|c|c|c|c|c|c|c|}
\hline \multicolumn{2}{|l|}{ Category } & \multicolumn{2}{|l|}{ Total } & \multicolumn{2}{|c|}{$<6 h r(n=395)$} & \multicolumn{2}{|c|}{$>6 \mathrm{hr}(\mathrm{n}=573)$} & \multirow[t]{2}{*}{$t$} & \multirow{2}{*}{$\begin{array}{l}\mathrm{p}- \\
\text { value }\end{array}$} \\
\hline & & Mean & SD & Mean & SD & Mean & SD & & \\
\hline \multicolumn{2}{|c|}{ Daily Total Patient } & 144.17 & 17.42 & 142.28 & 17.16 & 145.46 & 17.50 & -2.801 & .005 \\
\hline $\begin{array}{l}\text { Daily Total } \\
\text { Patient }\end{array}$ & $\begin{array}{l}\text { Level } \\
1\end{array}$ & 3.39 & 1.78 & 3.39 & 1.81 & 3.39 & 1.75 & -.046 & .963 \\
\hline \multirow[t]{4}{*}{ (Triage) } & $\begin{array}{l}\text { Level } \\
2\end{array}$ & 17.75 & 5.16 & 17.39 & 5.24 & 17.99 & 5.10 & -1.793 & .073 \\
\hline & $\begin{array}{l}\text { Level } \\
3\end{array}$ & 77.82 & 13.27 & 76.47 & 12.66 & 78.76 & 13.60 & -2.647 & .008 \\
\hline & $\begin{array}{l}\text { Level } \\
4\end{array}$ & 36.96 & 7.57 & 36.61 & 7.81 & 37.20 & 7.40 & -1.193 & .233 \\
\hline & $\begin{array}{l}\text { Level } \\
5\end{array}$ & 8.25 & 4.13 & 8.43 & 4.22 & 8.12 & 4.07 & 1.147 & .252 \\
\hline \multicolumn{2}{|c|}{ Occupancy rate } & 96.11 & 24.36 & 92.12 & 23.77 & 98.86 & 24.40 & -4.266 & $<.001$ \\
\hline
\end{tabular}

[Table 3. Relationship Interhospital Transfer handoff and Length of Stay] 


\begin{tabular}{|c|c|c|c|c|c|c|c|}
\hline Category & & $\begin{array}{l}\text { Prior } \\
\text { Communication }\end{array}$ & $\mathbf{N}$ & Mean & SD & $t$ & $\begin{array}{l}\text { p- } \\
\text { value }\end{array}$ \\
\hline \multirow[t]{4}{*}{ Triage } & \multirow[t]{2}{*}{ Level 1} & Yes & 63 & 300.0 & 333.2 & \multirow[t]{2}{*}{-2.931} & \multirow[t]{2}{*}{.004} \\
\hline & & No & 131 & 600.2 & 912.1 & & \\
\hline & \multirow[t]{2}{*}{ Level 2} & Yes & 195 & 812.4 & 977.9 & \multirow[t]{2}{*}{-1.589} & \multirow[t]{2}{*}{.113} \\
\hline & & No & 584 & 817.7 & 858.5 & & \\
\hline \multirow{6}{*}{$\begin{array}{l}\text { Severe Illness } \\
\text { diagnosis }\end{array}$} & \multirow[t]{2}{*}{ None } & Yes & 158 & 12.8 & 12.9 & \multirow[t]{2}{*}{-.974} & \multirow[t]{2}{*}{.330} \\
\hline & & No & 482 & 14.0 & 13.9 & & \\
\hline & $\begin{array}{l}\text { Severe } \\
\text { Emergency }\end{array}$ & Yes & 56 & 8.4 & 8.8 & \multirow[t]{2}{*}{-1.084} & \multirow[t]{2}{*}{.280} \\
\hline & Diagnosis & No & 160 & 10.3 & 11.8 & & \\
\hline & \multirow{2}{*}{$\begin{array}{l}\text { 4th } \\
\text { Emergency }\end{array}$} & Yes & 42 & 5.7 & 10.8 & \multirow[t]{2}{*}{-1.048} & \multirow[t]{2}{*}{.297} \\
\hline & & No & 70 & 8.0 & 11.7 & & \\
\hline \multirow{4}{*}{$\begin{array}{l}\text { Emergency } \\
\text { Operation or } \\
\text { Angiography) }\end{array}$} & \multirow[t]{2}{*}{ Yes } & Yes & 30 & 119.3 & 174.3 & \multirow[t]{2}{*}{-2.996} & \multirow[t]{2}{*}{.004} \\
\hline & & No & 36 & 254.8 & 297.6 & & \\
\hline & \multirow[t]{2}{*}{ No } & Yes & 228 & 762.0 & 922.3 & \multirow[t]{2}{*}{.328} & \multirow[t]{2}{*}{905} \\
\hline & & No & 679 & 805.6 & 883.7 & & \\
\hline \multirow[t]{4}{*}{ ICU admission } & \multirow[t]{2}{*}{ Yes } & Yes & 110 & 270.9 & 345.0 & \multirow[t]{2}{*}{-3.839} & \multirow[t]{2}{*}{$<.001$} \\
\hline & & No & 197 & 376.5 & 428.3 & & \\
\hline & \multirow[t]{2}{*}{ No } & Yes & 148 & 996.8 & 1039.0 & \multirow[t]{2}{*}{1.180} & \multirow[t]{2}{*}{.238} \\
\hline & & No & 518 & 930.5 & 946.5 & & \\
\hline \multirow{8}{*}{$\begin{array}{l}\text { Number of } \\
\text { Consultation }\end{array}$} & 0 & Yes & 58 & 294.5 & 415.4 & -1.929 & .055 \\
\hline & & No & 164 & 437.7 & 642.9 & & \\
\hline & 1 & Yes & 116 & 535.5 & 587.3 & -3.230 & .002 \\
\hline & & No & 328 & 644.5 & 659.7 & & \\
\hline & 2 & Yes & 49 & 759.4 & 749.0 & -1.885 & .061 \\
\hline & & No & 131 & 888.9 & 688.0 & & \\
\hline & 3 or more & Yes & 35 & 1740.3 & 1512.6 & .218 & .828 \\
\hline & & No & 92 & 1701.4 & 1353.8 & & \\
\hline
\end{tabular}

[Table 4. Performance Comparison of Various Algorithm-Based Prediction Models] 


\begin{tabular}{|llllll|}
\hline Model & Accuracy & Precision & Recall & F-measure & AUC of ROC \\
\hline Logistic Regression & 77.07 & 0.75 & 0.67 & 0.70 & 0.85 \\
\hline Random Forest & 76.84 & 0.74 & 0.67 & 0.70 & 0.83 \\
\hline Naïve Bayes & 76.19 & 0.77 & 0.60 & 0.67 & 0.83 \\
\hline Multilayer perceptron & 74.31 & 0.69 & 0.68 & 0.68 & 0.80 \\
\hline Decision Tree & 74.57 & 0.72 & 0.64 & 0.67 & 0.78 \\
\hline SVM & 76.53 & 0.77 & 0.62 & 0.68 & 0.74 \\
\hline Note: Except for random forest and naïve Bayes, which had the same AUC values, the differences \\
between the AUC of ROC of models were significant at a 95\% significance level.
\end{tabular}

\section{Figures}


[Figure 1. Comparison of the ROC Curves of Prediction Models (AUC values are in parentheses)]

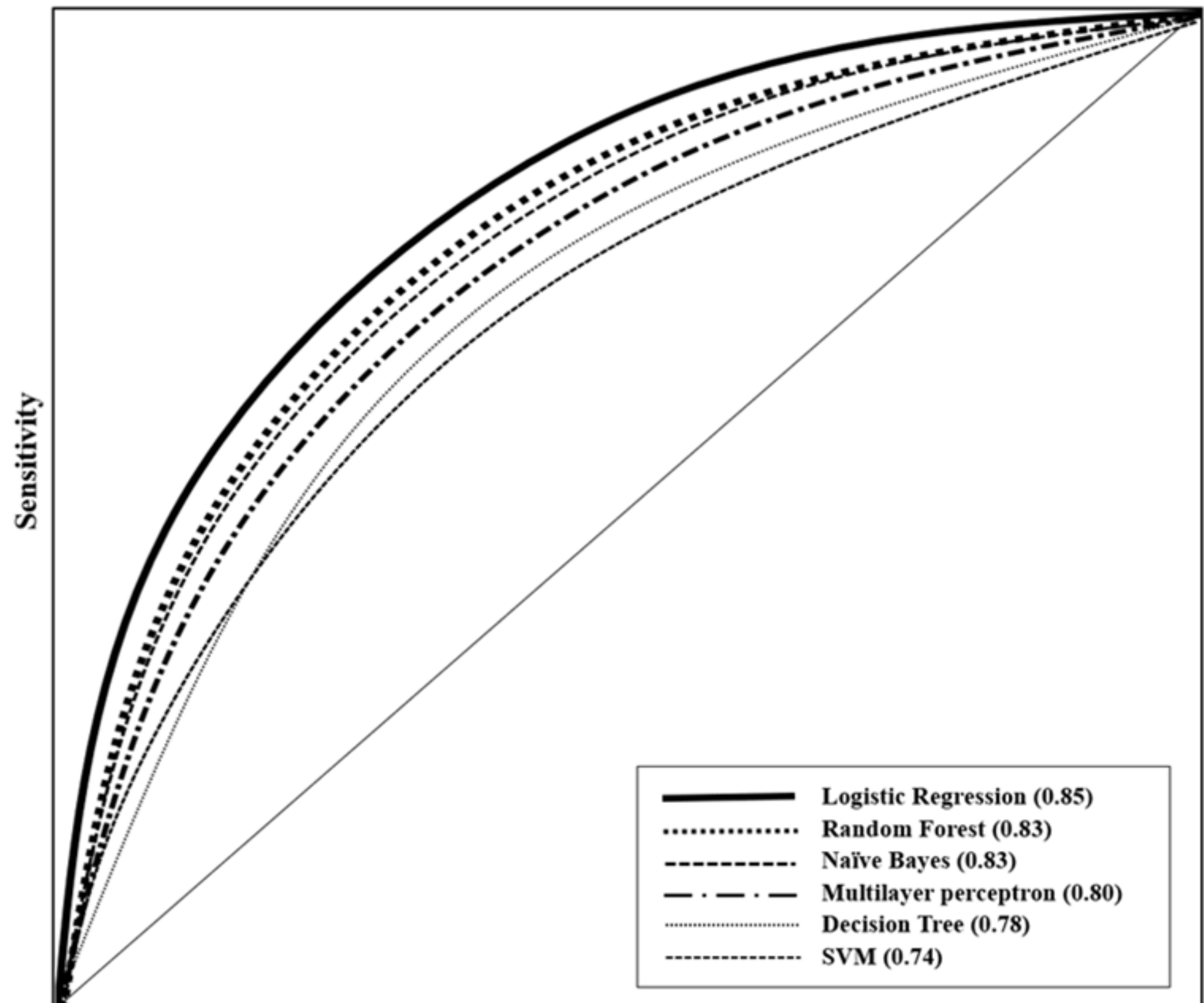

1-Specificity

Figure 1

"See image above for figure legend" 
[Figure 2. Odds Ratios of Factors Affecting 6-Hour-Or-Less Stays in the Emergency Department]

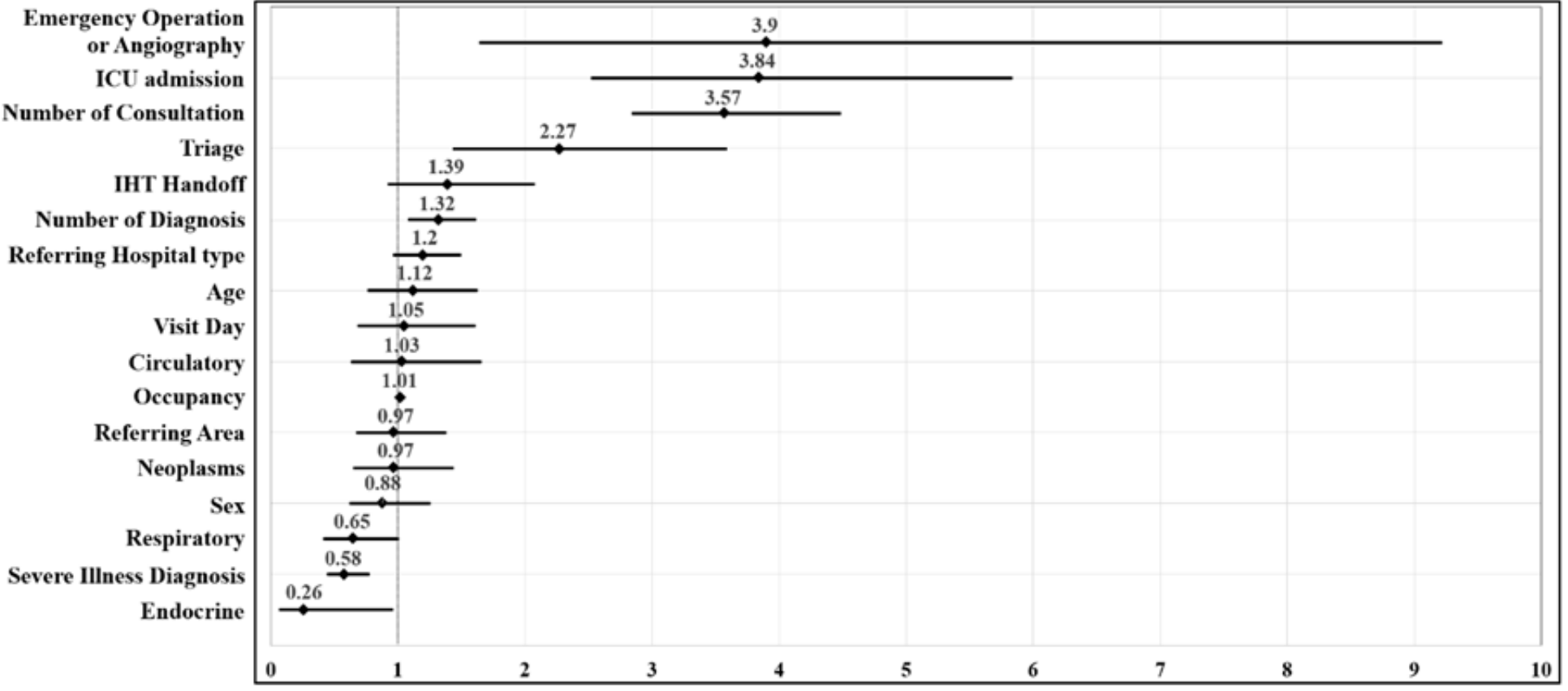

\section{Figure 2}

"See image above for figure legend" 